\title{
A $250 \mathrm{kHz}$ / 560 W PHASE MODULATED CONVERTER
}

\author{
A. Rajapandian \\ Department of Electrical Engineering \\ Indian Institute of Science \\ Bangalore 560012 INDIA
}

\author{
V. Ramanarayanan \\ Department of Electrical Engineering \\ Indian Institute of Science \\ Bangalore 560012 INDIA
}

\author{
R. Ramkumar \\ Department of Design and Engineering \\ Electrohms Private Limited \\ Bangalore 560012 INDIA
}

Abstract - Phase modulated full bridge topology, has recently emerged as the most suitable choice for high power, high voltage SMPS applications, requiring high power densities. Its distinguishing features are Zero Voltage Switching [ZVS] and constant frequency operation. In this paper, the various factors affecting the ZVS characteristics of this new topology are discussed in detail and design procedures for each of these components are developed. The concept of ZVS LIMTT is introduced. The various trade-offs involved in the design are brought out.

A full-nedged $560 \mathrm{~W} / 250 \mathrm{kHz}$ off-line SMPS, using the phase modulation concept is designed and developed. The simulated and experimental results are presented in detail.

\section{INTRODUCTION}

The present trend in switched mode power supplies is to switch at high frequencies, in the range of a few $\mathrm{MHz}$, with a view to achieve high power densities: The conventional hard switching converters are not suitable at such high frequencies due to the increased switching losses: Various soft switching converter topologies, with either Zero Current Switching [ZCS] or Zero Voltage Switching [ZVS], have been proposed. In the ZCS converters, the current through the device is made zero by external means, just prior to the turn-off of the device, thus eliminating the turn-off losses. In the ZVS converters, the voltage across the device is made zero, before turning on the device, thus totally eliminating the turn-on losses.

Resonant Load converters [1] and Resonant Switch converters [2] achieve soft switching by making the device current or the voltage sinusoidal, by adding extra resonating LC tank circuit and switching at the zero crossing instants of the current or the voltage. The main disadvantages of these converters are the increased device voltage / current stress typically 3 to 4 times that of the corresponding PWM topologies, and the higher conduction losses. Also the variable frequency operation of these converters, results in sub-optimal utilization of the filter components.

Resonant Transition converters, being proposed recently [3], combine the low switching loss characteristics of the resonant comverters and the low conduction loss and constant frequency characteristics of the PWM converters. The Phase Modulated Converter [PMC] presented in this paper, belongs to the class of Resonant Transition converters and offers ZVS transitions. Except for the resonant transitions, it is identical to the square wave PWM full bridge converter. The design principles for the two schemes are hence similar. Soft switching is achieved in PMC, relying mainly on the parasitic components like the magnetizing and leakage inductances of the power transformer, and the output capacitance of the Mosfet switch. These features make PMC the preferred topology for high voltage and high frequency applications.

\section{PRINCIPLE OF OPERATION}

The basic principle of operation of the phase modulated converter is fully brought out by the following three points.

- In any double ended converter, like the push-pull, half-bridge, full-bridge etc., it is possible to design for Zero Voltage switching, if the duty ratio is kept fixed at $50 \%$ [4].

- With the duty ratio fixed, schemes other than daty ratio control, have to be employed to control the output. In a full bridge converter, Phase Modulation, as explained in Fig. 1, is the simplest alternative scheme. Phase Modulation refers to varying the phase difference between the two arms, i.e., the phase difference between $V_{A}$ and $V_{B}$

- The output capacitance of the Mosfets $\left(\mathrm{C}_{\mathrm{DS}}\right)$ is quite significant, especially for high voltage and high frequency applications. This imposes the following two conditions to obtain ZVS.

1. a definite dead-time $T_{\text {Delay }}$ be allowed between the turn-off of a Mosfet and the turn-on of the complimentary Mosfet, in the same arm.

2. enough energy be stored in the parasitic inductances of the power transformer, to fully discharge the output junction capacitance of the Mosfets to be turned on.
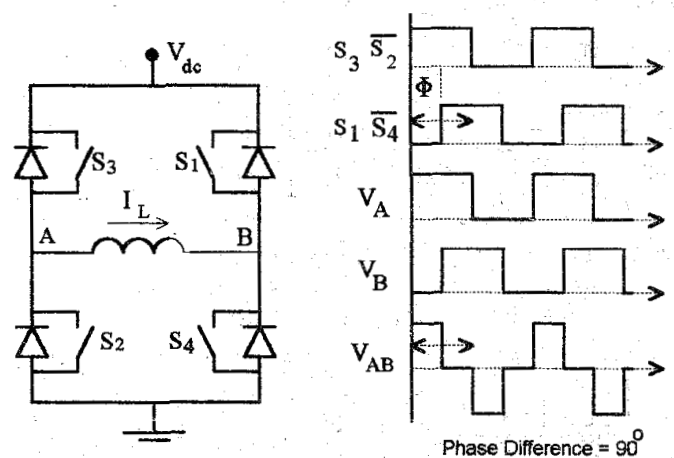

Fig. 1 a) Idealized schematic diagram of PMC

b) Waveforms corresponding to Phase difference of $90^{\circ}$ 


\section{ANALYSIS OF A COMPLETE CYCLE OF OPERATION}

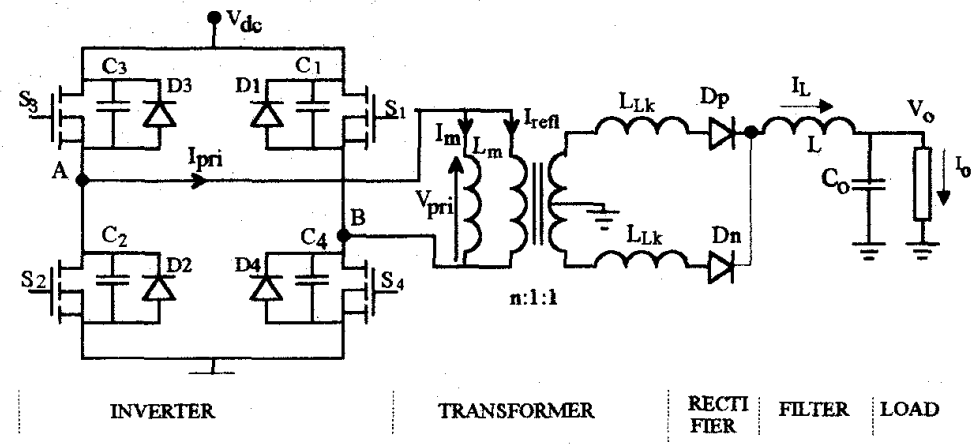

Fig. 2 Schematic diagram of PMC

Fig. 2 shows the schematic of PMC, used for analysis and simulation. As seen, the figure includes the parasitic elements like the output capacitances $\left(\mathrm{C}_{1}, \mathrm{C}_{2}, \mathrm{C}_{3}\right.$ and $\left.\mathrm{C}_{4}\right)$ of the Mosfets and the magnetizing $\left(\mathrm{Lm}_{\mathrm{m}}\right)$ and the leakage $\left(\mathrm{L}_{\mathrm{Lk}}\right)$ inductances of the transformer. (The Mosfet capacitances include the parasitic junction capacitance and any external snubber capacitor that may be added.)

For the purpose of analysis, a complete cycle of operation is divided into 8 distinct intervals for the inverter and 4 intervals for the secondary side rectifiers. The inverter and rectifier intervals are interdependent - the transformer primary currents are determined by the secondary side diode currents and the diode currents in turn depend on the magnitude and polarity of the inverter voltages. However, for ease of analysis they are considered separately.

The starting and ending of each of the inverter intervals are determined solely by the switching sequence of the devices. The equivalent circuits corresponding to each of the intervals are shown in Fig. 3. From these equivalent circuits, the governing equations valid in each interval are derived and listed in Table $I$.

TABLE I

INVERTER INTERVALS - SEQUENCE AND GOVERNING EQUATIONS

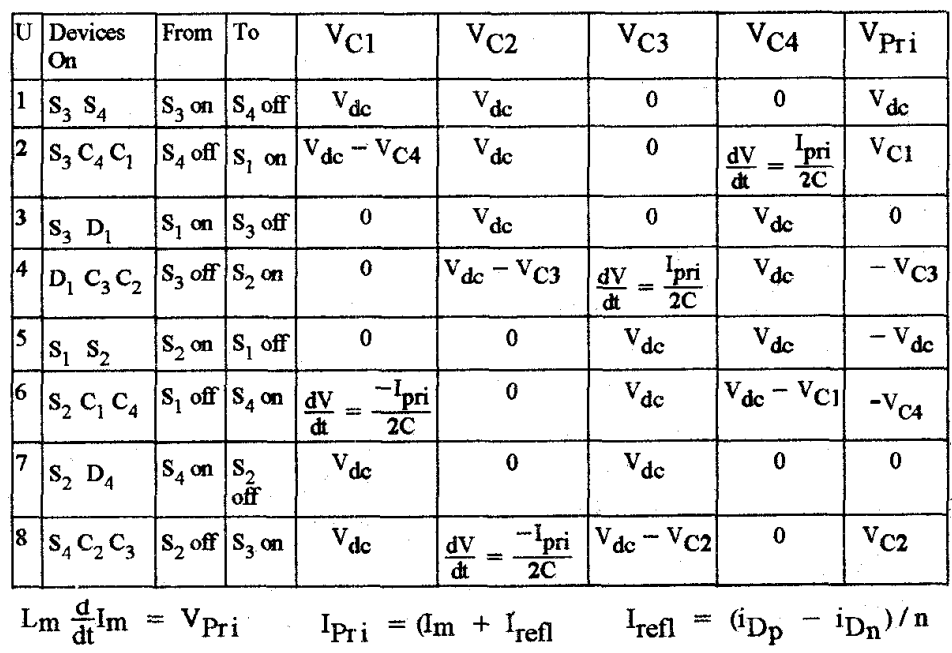

The rectifier intervals are determined by the transformer voltages and the diode currents. There are basically two types of rectifier intervals - the normal interval in which either $D_{p}$ or $D_{n}$ conducts and the overlap interval in which both the diodes conduct. The equivalent circuits corresponding to both these intervals are shown in Fig. 3 and the governing equations are given in Table II. The equations given in Tables I and II are used to simulate the converter. A more detailed discussion on the equivalent circuits and the governing equations is given in [4].

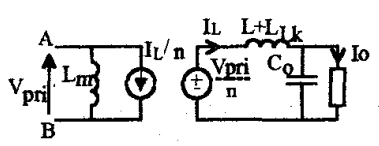

(a)

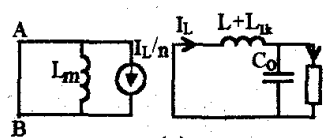

(c)
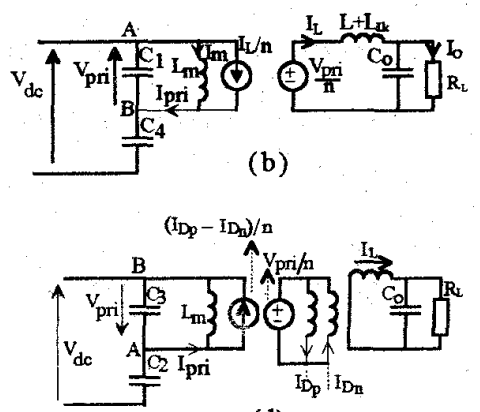

(d)

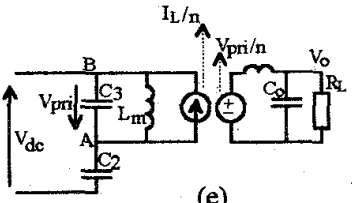

(e)

Fig. 3 Equivalent Circuits for Various Intervais a) inverter interval 1 and rectifier interval 1 b) inverter interval 2 and rectifier interval 1 c) inverter interval 3 and rectifier interval 1 d) inverter interval 4 and rectifier interval 1 e) inverter interval 4 and rectifier interval 2 


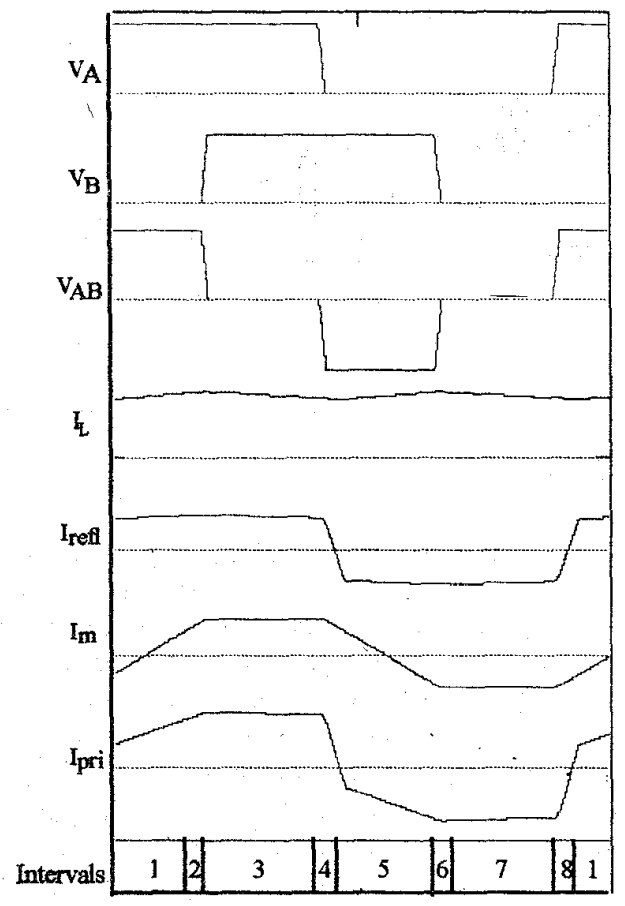

Fig, 4 Simulated waveforms of the Phase Modulated Converter

The equations listed in Tables I and II are used to simulate the phase modulated converter. The dynamic and steady-state characteristics of the converter are obtained from the simulation. Some of the simulated steady state waveforms of the converter are shown in Fig. 4 above.

\section{FACTORS AFFECTING ZVS}

ZVS demands that, prior to turn-on of a Mosfet, its output capacitance be completely discharged The discharge is to be accomplished by the transformer primary current. It is therefore essential that the primary current maintains the proper polarity till the capacitance is fully discharged. From the analysis of PMC in the previous sections, it is important to note that there are two types of transitions. One is from the power transfer mode to the freewheeling mode (inverter intervals 2 and 6 ) and the other is from the freewheeling to power transfer mode (inverter intervals 4 and 8 ). In the power transfer to freewheeling transition, both the magnetizing as well as the reflected load current components of the primary current maintain the proper polarity, throughout the transition. In the freewheeling to power transfer transition however, the reflected load component begins to reverse direction, the rate of reversal being determined by the leakage inductance. Hence the transition from the freewheeling to power transfer mode is more critical from the ZVS view point

From the above discussions, it is clear that large magnetizing current and leakage inductance result in the desired polarity for the primary current during the transitions and thus aid in ZVS. Another important factor that affects ZVS is the dead time $\mathrm{T}_{\text {Delay. }}$. As explained in Fig. 5, at heavy loads the total primary current reverses direction earlier than at light loads. Hence $\mathrm{T}_{\text {Delay }}$ has to be smaller at heavy loads. Ideally, $\mathrm{T}_{\text {Delay }}$ should be load dependent. The parameters affecting ZVS along with their effects are listed in Table III.

TABLE III

FACTORS AFFECTING ZVS AND THEIR QUALTATIVE EFFECTS

\begin{tabular}{|c|c|c|}
\hline VARIABLE & POSITIVE EFFECT & NEGATIVE EFFECT \\
\hline $\begin{array}{l}\text { Magnetizing } \\
\text { current }\end{array}$ & aids ZVS & $\begin{array}{l}\text { higher current stress and } \\
\text { conduction loss. }\end{array}$ \\
\hline $\begin{array}{l}\text { Leakage } \\
\text { inductance }\end{array}$ & $\begin{array}{l}\text { aids ZVS by reducing the } \\
\text { rate of reversal of the } \\
\text { primary current in the } \\
\text { imtervals } 4 \text { and } 8\end{array}$ & $\begin{array}{l}\text { reduces the max. effective duty } \\
\text { ratio; hence poor VA utilization } \\
\text { and more conduction loss. } \\
\text { increases ringing and dissipation } \\
\text { in the secondary rectifiers. }\end{array}$ \\
\hline $\mathbf{T}_{\text {Delay }}$ & {$\left[\begin{array}{l}\text { large } T_{\text {Ddy }} \text { aids ZVS at } \\
\text { light loads and affects } \\
\text { adversely at heavy loads }\end{array}\right]$} & $\begin{array}{l}\text { large } T_{\text {Dedy }} \text { reduces the effective } \\
\text { duty ratio and is particularly } \\
\text { undesirable at higher switching } \\
\text { frequencies. }\end{array}$ \\
\hline $\begin{array}{l}\text { Capacitance } \\
\text { across the } \\
\text { Mosfet - C }\end{array}$ & $\begin{array}{l}\text { large } C_{n s} \text { aids in loss less } \\
\text { tum-off }\end{array}$ & $\begin{array}{l}\text { large } C_{\mathrm{ps}} \text { demands more energy } \\
\text { to be stored in the transformer } \\
\text { inductances, hence bad for } 2 \mathrm{VS} \text {. }\end{array}$ \\
\hline
\end{tabular}

TABLE II

RECTIFIER INTERVALS - SEQUENCE AND GOVERNING EQUATIONS

\begin{tabular}{|c|c|c|c|c|c|c|c|}
\hline tot & Devices & From & To & $\mathrm{i}_{\mathrm{D}_{\mathrm{p}}}$ & ${ }^{i} D_{n}$ & $v_{\text {in }}$ & $\mathrm{L}^{*}$ \\
\hline 1 & $D_{p}$ & $\mathrm{i}_{\mathrm{D}_{\mathrm{n}}} \leq 0$ & $\mathrm{v}_{\mathrm{sec}} \leq \frac{\mathrm{L}_{\mathrm{Ik}}}{2} \frac{\mathrm{di}_{\mathrm{D}_{\mathrm{p}}}}{\mathrm{dt}}$ & $i_{L}$ & 0 & $v_{\mathrm{sec}}$ & $L+L_{L k}$ \\
\hline 2 & $D_{p} D_{n}$ & $V_{s e c} \leq \frac{L_{1 k}}{2} \frac{d_{i} D_{p}}{d t}$ & ${ }^{i_{p}} \leq 0$ & ${ }^{i} L-{ }^{i} D_{n}$ & $\frac{\mathrm{di}}{\mathrm{dt}}=\frac{-v_{\mathrm{sec}}}{\mathrm{L}_{\mathrm{Lk}}}$ & 0 & $\mathrm{~L}$ \\
\hline 3 & $\mathrm{D}_{\mathrm{n}}$ & ${ }^{i} D_{p} \leq 0$ & $v_{\text {sec }} \geq \frac{-L_{L k}}{2} \frac{\text { di }_{D_{n}}}{d n}$ & 0 & $i_{L}$ & $-V_{\text {sec }}$ & $L+L_{L k}$ \\
\hline 4 & $D_{p} D_{n}$ & $v_{s e c} \geq \frac{-L_{L k}}{2} \frac{d D_{p}}{d t}$ & $\mathrm{i}_{\mathrm{D}_{\mathrm{n}}} \leq 0$ & $\frac{\mathrm{di}}{\mathrm{dt}}=\frac{\mathrm{V}_{\mathrm{sec}}}{\mathrm{L}_{\mathrm{Lk}}}$ & $i_{L}-i_{D_{p}}$ & 0 & $\mathrm{~L}$ \\
\hline
\end{tabular}

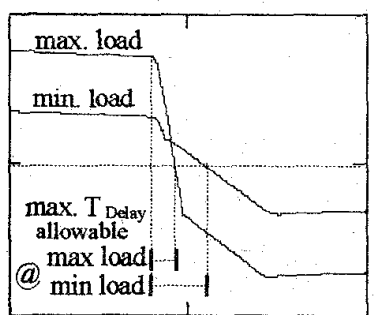

$$
L^{*} \frac{d}{d t} i_{L}=V_{i n}-V_{O} \quad C_{0} \frac{d}{d t} V_{O}=i_{L}-I_{0}
$$

Fig. 5 Total Primary current at different loads 


\section{DESIGN CONSIDERATIONS TO ACHIEVE ZVS}

From the equations valid for the fourth inverter interval (which is the crucial interval for ZVS) the following expression for the voltage across the Mosfet to be turned on, can be derived [4]

$$
\mathrm{V}_{\mathrm{C} 2}=\mathrm{V}_{\mathrm{dc}}-\left(\mathrm{Im}+\mathrm{I}_{\mathrm{refl}}\right) \sqrt{\frac{\mathrm{L}_{\mathrm{eq}}}{2 \mathrm{C}_{\mathrm{eq}}}} \sin \omega \mathrm{t}
$$

where,

$$
\begin{aligned}
& \omega=\frac{1}{\sqrt{2 \mathrm{Leq}_{\mathrm{Ceq}}}} \\
& \mathrm{Leq}_{\mathrm{eq}}=\mathrm{L}_{\mathrm{Lk}}^{*} / \mathrm{Lm} \\
& \mathrm{L}_{\mathrm{Lk}}^{*}- \text { leakage inductance referred to the primary. } \\
& \mathrm{Ceq}^{-}-\text {capacitance across the Mosfet (intrinsic and external) }
\end{aligned}
$$

The above expression gives the following two conditions to achieve ZVS at any given load.

$$
\begin{aligned}
& \text { 1. }\left(\mathrm{Im}+\mathrm{I}_{\text {refl }}\right) \sqrt{\frac{\mathrm{L}_{\mathrm{eq}}}{2 \mathrm{C}_{\mathrm{eq}}}} \geq \mathrm{V}_{\mathrm{dc}} \\
& \text { 2. } \mathrm{T}_{\text {Delay }}=\frac{\pi}{2} \sqrt{2 \mathrm{C}_{\text {eq Leq }}}
\end{aligned}
$$

The first condition ensures that the peak of the sinusoidal component of (1) is atleast equal to $V_{d c}$, so that $V_{C 2}$ eventually reaches zero. The second condition ensures that the Mosfet is switched on when $\mathrm{V}_{\mathrm{C} 2}$ is zero. Hence the design strategy is as follows.

- select $\mathrm{T}_{\text {Delay }}$ considering the switching frequency and the Mosfet characteristics. Ceq is initially taken as equal to the average output capacitance of the Mosfet (intrinsic alone).

- calculate the value of $L_{e q}$ from (3), with the above value of $\mathrm{T}_{\text {Delay }} \cdot \mathrm{L}_{\mathrm{Lk}}^{*}$ is approximately equal to $\mathrm{Leq}$

- with the above value of $\mathrm{L}_{\mathrm{Lk}}$, calculate from (2), the peak magnetizing current required for any given load condition, and finally the magnetizing inductance required.

The full system may be numerically simulated with the help of equations listed in Tables I and II, and using the above values for delay time, magnetizing current and leakage inductance as initial estimates. From repeated simulation runs more satisfactory design values for all the parameters may be obtained.

From (1) it is clear that at light loads, larger magnetizing current and leakage inductance are needed to achieve ZVS, resulting in increased conduction losses. Hence ZVS down to no load results in high total losses at full load. On the other hand, ZVS only at and near full load, results in high switching losses at light loads. Hence a compromise between these two conflicting requirements has to be arrived at. The optimum choice for the load down to which ZVS is obtained [ZVS LIMIT] depends on various factors like the operating frequency, nominal load range, characteristics of the chosen Mosfet and the range of input voltage variations.

\section{DEVELOPMENT OF A $250 \mathrm{kHz}$ / $560 \mathrm{~W}$ OFF-LINE PMC}

The design and development of a PMC of the following specifications are discussed in this section.

$\begin{array}{ll}\text { Input } & 150 \mathrm{~V} \text { to } 270 \mathrm{~V} \mathrm{AC}, 50 \mathrm{~Hz} \\ \text { Output Voltage } & 28 \mathrm{~V} \mathrm{DC} \\ \text { Maximum output current } & 20 \mathrm{~A} \text { (nominal power }=560 \mathrm{~W} \text { ) } \\ \text { Output regulation } & <0.1 \% \\ \text { Output ripple } & <0.5 \% \\ \text { Switching frequency } & 250 \mathrm{kHz}\end{array}$

The first step in the design is to decide the ZVS LIMIT. For the above specifications and for the chosen Mosfets (IRFP 460) with $R_{D S}$ on of about $0.3 \Omega$, the loss curves at various ZVS LIMITs are obtained as shown Fig. 6. From these loss curves the ZVS LIMIT is chosen as $16 \mathrm{~A}$, so that the total losses at the nominal load range is minimum. The values of magnetizing and leakage inductances and the $\mathrm{T}_{\text {Delay }}$ needed are then calculated using the procedures discussed previously. The values thus obtained are,

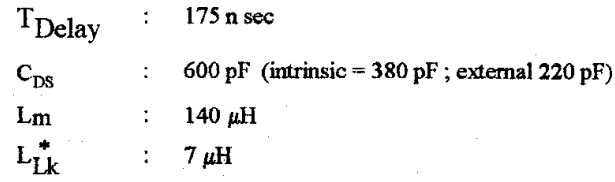

\section{A. Power Transformer and Inductors}

For the chosen $\mathrm{L}_{\mathrm{Lk}}$ the loss of effective duty ratio due to the overlap effect is determined from simulation. The transformer turns ratio is then selected considering the reduced maximum duty ratio available and the minimum DC link voltage. The designed values of the magnetizing and leakage inductances are realised through separate external inductors. Both the transformer and the inductors are made of high frequency ferrite materials (A43 - Webel). They are operated at low flux densities $(<0.1 \mathrm{~T})$ to reduce the core losses. The windings are made of copper foil of $70 \mu$ thickness. The magnetizing inductance may easily be integrated into the power transformer by introducing appropriate air gap.

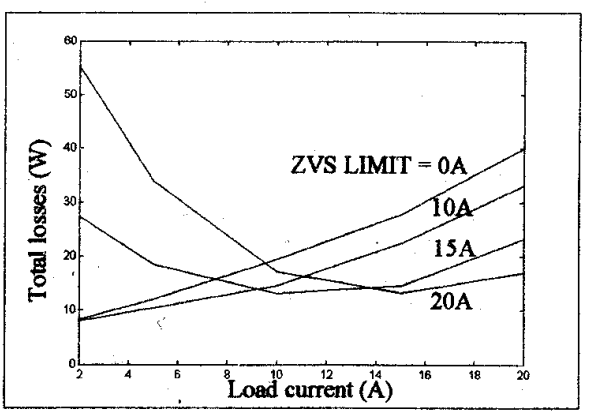

Fig. 6 Loss curves for different ZVS LIMTTs 


\section{B. Filter Components}

The design of output filter inductor and capacitor is identical to that of the full bridge PWM converter [6]. The inductor is designed to operate in the continuous current mode [CCM] down to 5\% load and the capacitor is designed to make the ripple voltage less than $0.5 \%$. The values obtained for these components are,

$$
\begin{array}{lll}
\text { Filter inductance } & : & 18 \mu \mathrm{H} \\
\text { Filter capacitance } & : & 2000 \mu \mathrm{F}(\mathrm{ESR} \approx 100 \mathrm{mM})
\end{array}
$$

High frequency core materials are not needed for the filter inductor since the high frequency $\mathrm{AC}$ component of the inductor current is very small.

\section{Drive Circuit}

In the drive circuit shown in Fig. 7 , the transistor $Q_{1}$ ensures fast turn-off ( $<100 \cdot \mathbf{n} \mathrm{sec}$ ) of the Mosfet, thus reducing the turn-off losses. The turn-off time can be controlled through the resistor $R_{b}$. The turn-on is made relatively slower since it is a lossless transition. The buffer stage indicated in the figure is made of complementary $P$ and $\mathrm{N}$ channel Mosfets with low input capacitances.

\section{Control Circuit}

The phase modulation controller IC, ML 4818 is used to obtain the drive signals for all the four Mosfets [5 ]. It features both current mode control as well as voltage mode control with feed forward feature. The dead time $\mathrm{T}_{\text {Delay }}$ is programmable through an external resistor. For low power applications, the IC can directly drive the main .Mosfets without the external buffer stage

\section{E. Closed Loop Compensators}

The small signal dynamic model of PMC is similar to the PWM full bridge topology, since from a purely a control point of view, phase shift control is analogous to pulse width control. However, the large leakage inductance results in a slight deviation from the PWM model. But for practical compensator design, this difference may be neglected, as it affects mainly the $Q$ factor alone in the model. The model derived for the PWM case is given below [6].

$$
\frac{\tilde{V}_{0}(s)}{\widetilde{d}(s)}=\frac{V_{d c}\left(1+s C_{o} R_{E S R}\right)}{1+\frac{s}{Q \omega}+\frac{s^{2}}{\omega^{2}}} \quad \text { where, } \omega=\sqrt{\frac{1}{L_{0}}}
$$

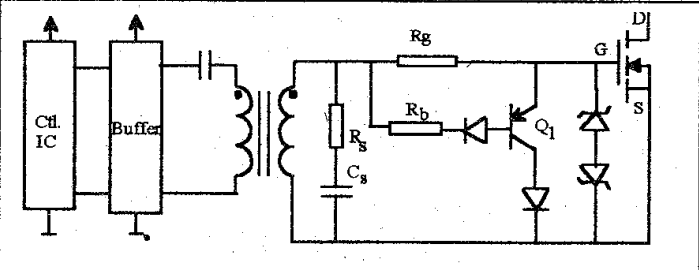

Fig. 7 Mosfet gate drive circuit

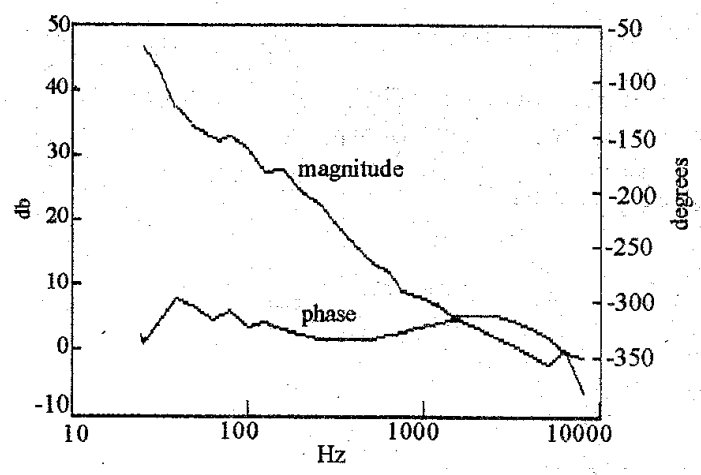

Fig 8 Measured overall loop gain $(-A \beta)$ of the converter Phase Margin $=(360-270)=90^{\circ}$

The same model is verified for the case of PMC by step response of the simulated system. The compensator is designed such that the overall loop gain falls with a single slope over the entire frequency range of interest. The design involves placing two zeroes at the LC corner frequency to cancel the complex poles, a pole at the origin for steady state accuracy and another pole near the ESR zero. The measured loop gain for the converter is given in Fig. 8.

\section{EXPERIMENTAL RESULTS}

\section{A. Output Regulation By Phase Modulation}

Output regulation better than $0.1 \%$ over the entire line and load ranges is obtained by phase modulation. Fig 9 shows how the phase difference is controlled to regulate the output voltage as the input varies from 150 to $270 \mathrm{~V} \mathrm{AC}$.
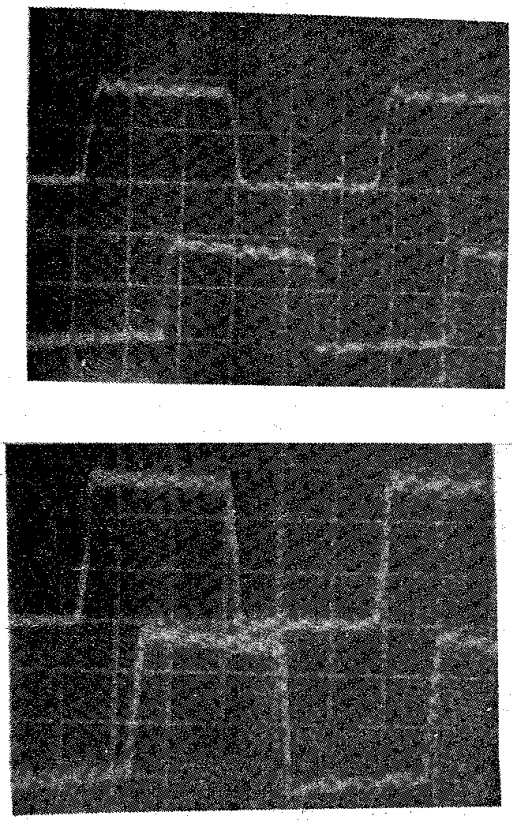

Fig, $9 \mathrm{~V}_{\mathrm{A}}$ and $\mathrm{V}_{\mathrm{B}}$ at $150 \mathrm{VAC}$ (top) and $270 \mathrm{VAC}$ (bottom) (Vert: $125 \mathrm{~V} / \mathrm{div}$; Hori: $0.66 \mathrm{u} \mathrm{sec} / \mathrm{div}$ ) 


\section{B. ZVS and Non-ZVS Turn-On Transitions}

The transformer primary voltage gives information about the turn-on transitions of all the four Mosfets. Fig. 10, shows the simulated and experimental waveforms of the transformer primary voltage $\left(\mathrm{V}_{\mathrm{AB}}\right)$ and current $\left(\mathrm{I}_{\mathrm{AB}}\right)$ corresponding to a load current of $6 \mathrm{~A}$. Fig. 10c shows the $V_{D S}$ and $V_{G S}$ waveforms corresponding to the turn-on transition in the freewheeling to power transfer mode. As seen the transition takes place with about $180 \mathrm{~V}$ across the switch. This loss of ZVS is due to the insufficient energy stored in the transformer inductances. However the turn-on in the other transition is ZVS. Fig. 11, shows the same waveforms for a load current of $18 \mathrm{~A}$. As seen, the increased reflected load current results in ZVS for all the transitions. Fig. 11c, shows the $V_{D S}$ and $V_{O S}$ waveforms for . the freewheeling to power transfer turn-on transition. As seen, $V_{D S}$ falls to zero well before the gate reaches the threshold voltage.

\section{ZVS LIMIT and Mosfet Losses}

The ZVS LIMTT chosen in the design is $16 \mathrm{~A}(80 \%$ load). The values for the magnetizing and leakage inductances and the dead time $\mathrm{T}_{\text {Delay, }}$, are obtained from simulation. With these values, ZVS is obtained in the actual converter, from full load down to $16.6 \mathrm{~A}$. By varying the magnetizing inductance, the performance of the converter under various ZVS LIMITs is studied. The results thus obtained for two ZVS LIMITs - $60 \%$ and $80 \%$ load - are listed in Table IV.
TABLE IV

CONVERTER PERPORMANCE AT TWO DIFFERENT ZVS LIMTTS

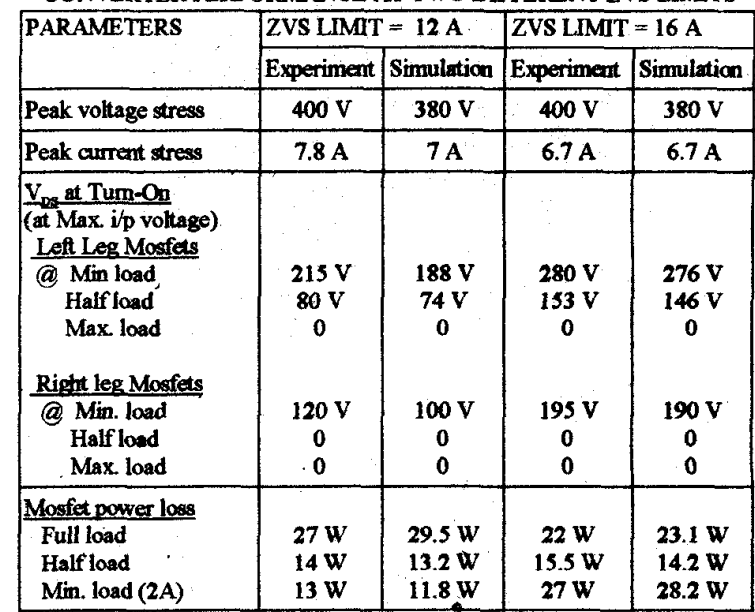

\section{Turn-Off Transition}

The turn-off transitions depend on the capacitances across the device (intrinsic and external) and the fall time of the Mosfet. The drive circuit shown in Fig. 7 ensures low fall time. Fig. 12 shows the $V_{D s}$ and $V_{G s}$ waveforms during the turn-off transition, at full load. By the time $V_{C s}$ falls below the threshold of nearly $2 \mathrm{~V}$, (representing zero device current) the $V_{\mathrm{Ds}}$ rises only by about $30 \mathrm{~V}$. Hence turn-off losses are small.
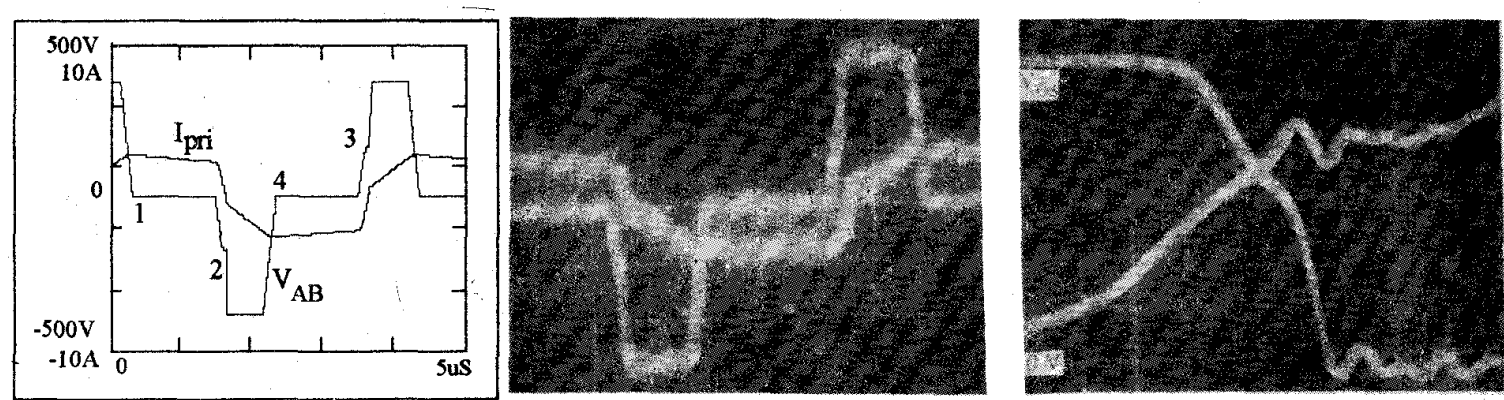

Fig. 10 Waveforms corresponding to 6A load (below ZVS LIMTT) (a) Simulated waveforms of primary voltage and current. 1,2,3 and 4 represent the instants when $\mathrm{S}_{\mathrm{I}}, \mathrm{S}_{2}, \mathrm{~S}_{3}$ and $\mathrm{S}_{4}$ are tumed on. (b) Experimental waveforms of the same parameters shown in (a). $\left(\mathrm{V}_{\mathrm{AB}} ; 125 \mathrm{~V} / \mathrm{div} \mathrm{I}_{\mathrm{AB}}: 2.5 \mathrm{~A} / \mathrm{div} \mathrm{Hori}: 0.5 \mathrm{usec} / \mathrm{div}\right)$

(c) $\mathrm{V}_{\mathrm{DS}} \mathrm{VS}_{\mathrm{S}} \mathrm{V}_{\mathrm{GS}}$ during the tum-on transition from freewheeling to power transfer mode $\left(\mathrm{V}_{\mathrm{DS}}: 60 \mathrm{~V} / \mathrm{div} \mathrm{V}_{\mathrm{GS}}: 5 \mathrm{~V} / \mathrm{div} \mathrm{Hori}: 50 \mathrm{nsec} / \mathrm{div}\right)$
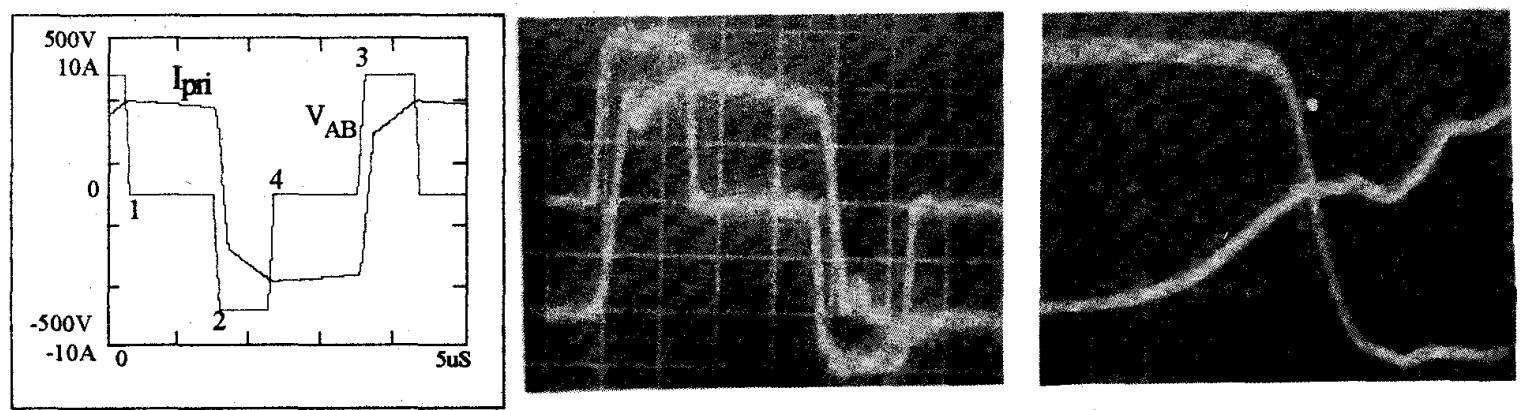

Fig. 11 Same waveforms as that of Fig 10, but corresponding to load current of 18A (above ZVS LIMT). Note that all the transitions are ZVS. Also note that the $V_{D S}$ falls to zero even before $V_{G S}$ reaches the threshold level 


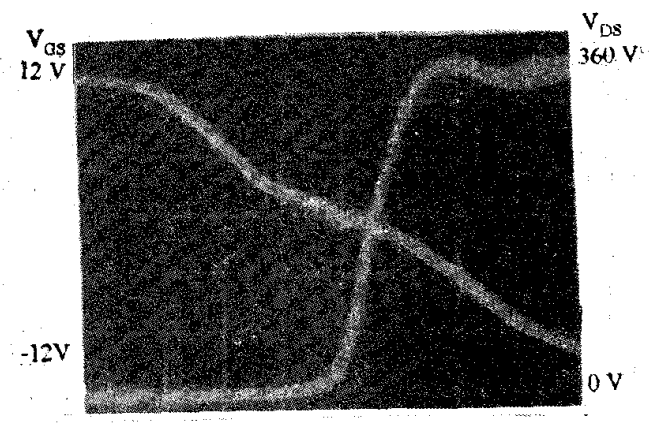

Fig. $12 V_{D S}$ Vs. $V_{\text {os }}$ during tum-off

\section{E. Left Leg And Right Leg Transitions}

As explained earlier, the left leg and right leg transitions are quite different from the ZVS view point. In the left leg Mosfets, the intrinsic diode conducts only during the transients. In the right leg Mosfets, the diode conducts for almost as much time as the Mosfet channel. Achieving ZVS for these Mosfets is relatively easier. Figures 13 and 14, show the Mosfet voltages and the primary current (which is equal to the device current when it is on) for the left leg and right leg Mosfets.

\section{CONCLUSIONS}

The Phase Modulated Full bridge Converter, with ZVS characteristics and fixed frequency control, is proposed as the topology of choice for high voltage and high power applications which require high power densities. Design
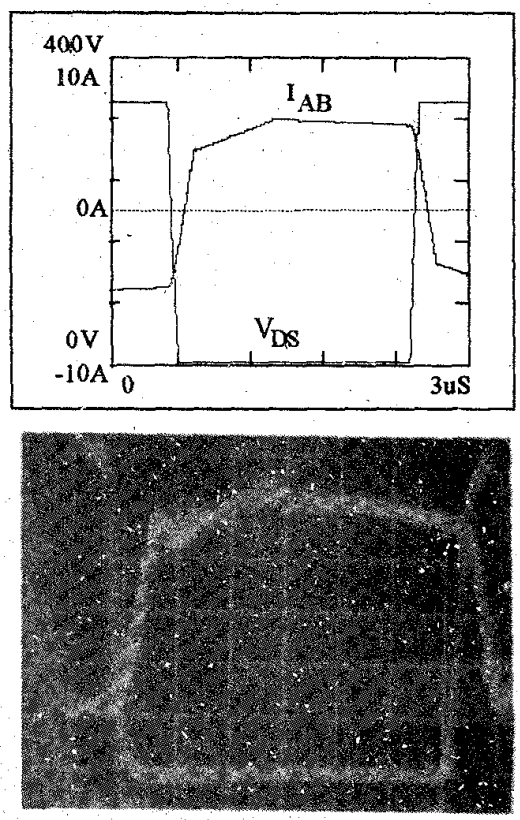

Fig. 13. $V_{D S}$ Vs. $I_{A B}$ for right leg Mosfets. $I_{A B}$ is equal to the device current when $V_{D S}$ is zero. Note that the device voltage falls to zero, before the current through it becomes positive.
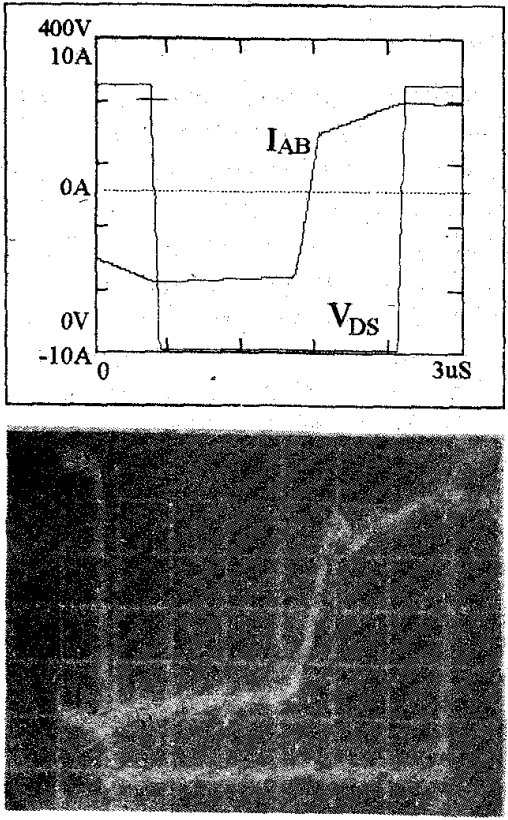

Fig. 14. $V_{D S}$ Vs. $I_{A B}$ for right leg Mosfets. The intrinsic diode conducts for the major part (negative current with $\mathrm{V}_{D s}$ zero) $\mathrm{V}_{D \mathrm{DS}}: 60 \mathrm{~V} / \mathrm{div} \mathrm{I}_{\mathrm{AB}}: 2.5 \mathrm{~A} / \mathrm{div}$

procedures for the various components to achieve ZVS are developed. Results obtained on a $560 \mathrm{~W} / 250 \mathrm{kHz}$ off-line phase modulated converter are presented.

The advantages of PMC are more striking in applications where the range of input variation is not too wide. One such important application area is in high power converters with front end Power Factor Control [PFC] scheme.

ZVS down to no load, though possible, results in very high conduction losses. ZVS LIMIT, defined as the load down to which ZVS is obtained, is therefore an important factor to be considered in the design. The optimum choice depends on many parameters like the operating frequency, Mosfet characteristics, line and load variations etc. apart from cost and size considerations. Digital simulation is a very useful tool in deciding and then designing for the most satisfactory value of ZVS LIMTT, for any particular application.

\section{ACKNOWLEDGMENTS}

The authors wish to thank M/s. Electrohms Pvt. Ltd., Bangalore, for sponsoring this project.

\section{REFERENCES}

[1] R.L.Steigerwald, "A comparison of half-bridge resonant converter topologies." IEEE Trans. Power Electronics, Jan 1987, pp. 174-182. [2] S. Freeland and R.D. Middlebrook, "A unified analysis of converters with resonant switches." IEEE Proc. PESC 1987 Record, pp. 20-30.

[3] G. Hua, C. Leu, F.C. Iee, "Novel zero voltage transition PWM converters." IEEE Proc. PESC 1992 Record, pp. 55-61

[4] A. Rajapandian, "A constant frequency resonant transition converter." M.Sc (Engg) Thesis, Dept. of Elect. Engg., Indian Inscitute of Science.

[5] "Phase modulated PWM topology with the MLA818." Micro Linear application note -19 , June 1992 .

[6] N. Mohan, Undeland and Robbins, "Power Electronics: Converters, Applications and Design." John Wiley and Sons, Newyork. 